\title{
Primary hypertension and special aspects of hypertension in older children and adolescents
}

This article was published in the following Dove Press journal:

Adolescent Health, Medicine and Therapeutics

27 July $201 \mathrm{I}$

Number of times this article has been viewed

\section{Demetrius Ellis \\ Yosuke Miyashita \\ Children's Hospital of Pittsburgh of UPMC, University of Pittsburgh School of Medicine, PA, USA}

Correspondence: Yosuke Miyashita

Children's Hospital Drive,

440I Penn Ave, Pittsburgh,

PA I5224, USA

Tel + I 4126925182

Fax + I 4I26927443

Email yosuke.miyashita@chp.edu

\begin{abstract}
The prevalence of hypertension has increased at an accelerated rate in older children and adolescents. This has raised great concern about premature development of cardiovascular disease, which has major long-term health and financial implications. While obesity and sedentary habits largely explain this phenomenon, there are other social and cultural influences that may unmask genetic susceptibility to hypertension in the pediatric population. While it is essential to exclude numerous causes of secondary hypertension in every child, these disorders are not discussed in this review. Rather, the aim of this review is to familiarize pediatricians with casual and ambulatory blood pressure measurement, epidemiology, pathophysiology, and management of several common conditions that play a role in the development of hypertension in children and adolescents. Besides primary hypertension and obesity-related hypertension, emphasis is given to epidemiology, measurement of blood pressure, including ambulatory blood pressure monitoring, hypertension associated with drug use, teenage pregnancy, and video and computer games. Lastly, because pediatricians are increasingly confronted with special issues concerning the management of the hypertensive athlete, this topic is also addressed.
\end{abstract}

Keywords: hypertension, adolescents, obesity, drugs, pregnancy, athletes

\section{Introduction}

The prevalence of secondary hypertension has increased only marginally as a result of measurement of blood pressure by pediatricians at more regular intervals. However, the prevalence of primary hypertension has increased from $1.0 \%$ to $4.5 \%$ over the period 1993-2004. ${ }^{1-6}$ Environmental and social factors leading to obesity are largely responsible for this alarming rise in the prevalence of primary hypertension. A culture of excessive television viewing and video and computer gaming leading to sedentary habits, high consumption of calories, salt and caffeine, and recreational drug use are among other leading contributors to this trend. These influences, coupled with a genetic predisposition to hypertension, are a recipe for cardiovascular injury during childhood or in early adulthood. Thus, hypertension is increasingly viewed as a continuum, with many similarities and considerations being applicable to older children as those recommended for adults with hypertension. ${ }^{7}$ Moreover, the long-term cardiovascular morbidity, mortality, and cost of undiagnosed hypertension and of uninterrupted unhealthy lifestyle habits leading to primary hypertension in the pediatric age group, are incalculable.

A comprehensive review of the causes, pathophysiology, and pharmacotherapy of secondary hypertension in children is beyond the scope of this review. However, the reader is referred to several such reviews. ${ }^{8-10}$ The focus of the current report is to 
discuss selectively several special aspects of hypertension pertinent to older children and adolescents, in which the role of pediatricians in the recognition, prevention, evaluation, and management is essential. These disorders include primary hypertension and the influence of obesity, dietary, and other lifestyle measures; hypertension associated with use or abuse of prescribed or illicit drugs; hypertension associated with teenage pregnancy; and the emerging influence of video and computer games on the development of hypertension. We also discuss the evaluation and management of the hypertensive athlete, which presents unique challenges in the adolescent population.

\section{Blood pressure measurement}

The proper measurement of blood pressure in children and definitions of hypertension are detailed in excellent publications by several task forces. ${ }^{11-13}$ The Fourth Report from the National High Blood Pressure Program Working Group on Children and Adolescents is a cornerstone in the education of pediatricians on this increasingly important topic. ${ }^{11}$ The latest 2004 report emphasizes the need to measure blood pressure not only in children with conditions predisposing to hypertension, but in all children over three years of age. It also redefines the reference range between blood pressure $\geq$ the 90 th percentile and $<$ the 95 th percentile from "high normal" to "prehypertension". The latter definitions parallel the definitions established by a task force addressing hypertension in adults, ${ }^{7}$ and implies the need for preventive counseling and for taking appropriate steps to identify target organ injury, even at this early stage. This evidence-based report also stressed obesity as a key contributor to primary hypertension in children. Another seminal report emphasized the unquestioned value of characterizing blood pressure by ambulatory blood pressure monitoring (ABPM) in children suspected of having "white coat" or "masked" hypertension (see ABPM section). ${ }^{13}$

On a practical level, there are multiple devices that may be used for screening of hypertension. Wrist or finger devices have not been well validated and are not recommended. Table 1 indicates the advantages and disadvantages of these methods. Oscillometric devices, such as the Dinamap ${ }^{\circledR}$, used in many hospitals and clinics, provide reliable measurements but are expensive. They are particularly useful in infants and younger children in whom manual blood pressure measurement by auscultation of Korotkoff sounds may be difficult. Blood pressure obtained by oscillatory measurement tends to be 5-10 $\mathrm{mmHg}$ higher than auscultatory or manual blood pressure measurement. Therefore, if these blood
Table I Advantages and disadvantages of automated and manual methods used to measure blood pressure

\begin{tabular}{ll}
\hline Automated/oscillometric & Manual \\
- Pros & - Pros \\
- Ease of use & - Most accurate \\
- Good for screening & - Good for confirming \\
- Home use & hypertension \\
- Infants/small children & - Cons \\
- Repeated measures & - Observer error \\
- Not affected by cuff placement & - Noise interference \\
- Wrist cuff available & - Motion interference \\
- Cons & - Difficult in infants/ \\
$-\quad$ Measures mean arterial pressure & small children \\
$\quad$ then calculates systolic and diastolic & - Mercury: \\
$\quad$ blood pressure & environmental hazard \\
- Manufacturer variability & - Aneroid: loses accuracy \\
- Vibrations & over time \\
\hline
\end{tabular}

pressures are normal for age, gender, and height, they suffice for screening and for excluding hypertension. In contrast, oscillometric blood pressure values $\geq$ the 95th percentile must be confirmed by manual measurement in the upper and lower extremities utilizing an appropriate size cuff, because this method is more accurate and correlates best with the blood pressure norms that were originally compiled based on manual blood pressure measurements. If blood pressure is elevated, it should be repeated and the average of three such manual values during a single clinic visit may be recorded as the representative blood pressure for the child. Such children then undergo further screening for hypertension on three consecutive visits one week apart, because on rescreening, the prevalence of hypertension falls from $19 \%$ to $4.5 \%{ }^{3}$

Table 2 summarizes the definitions of hypertension based on casual manual blood pressure measurements. If the blood pressure remains $\geq$ the 95 th percentile, referral to a pediatric nephrologist or cardiologist who specializes in the evaluation and management of hypertension is recommended. The task is then to exclude secondary causes of hypertension which predominate in preadolescent children, and may require extensive investigation and unique therapies.

In order to detect white coat or masked hypertension, the use of ABPM is essential. Table 3 summarizes the definitions of hypertension based on normative ABPM data obtained in 949 healthy white German school children aged 5-20 years. ${ }^{14}$ White coat hypertension is defined by casual office or clinic blood pressure $>$ the 95 th percentile but normal blood pressure by ABPM, while masked hypertension is defined as the converse of white coat hypertension. Because target organ injury depends largely on the average blood pressure load, this may be the best measure of hypertension and is 
Table 2 Hypertension classification by casual blood pressure measurement, frequency of measurement, and therapy recommendations*

\begin{tabular}{|c|c|c|c|}
\hline & Prehypertension & Stage I hypertension & Stage II hypertension \\
\hline Systolic BP & 90-94th percentile or & Systolic BP or diastolic BP & Systolic BP or diastolic BP \\
\hline or diastolic & if $\mathrm{BP}$ exceeds $\mathrm{I} 20 / 80 \mathrm{mmHg}$ & 95-99th percentile plus $5 \mathrm{mmHg}$ & percentile $>99$ th percentile \\
\hline BP percentile & even if $<90$ th percentile & & plus $5 \mathrm{mmHg}$ \\
\hline $\begin{array}{l}\text { Frequency of BP } \\
\text { measurement }\end{array}$ & Recheck in six months & $\begin{array}{l}\text { Recheck in I-2 weeks or sooner; if child is } \\
\text { symptomatic; if hypertension is persistent, } \\
\text { evaluate on } 2 \text { additional occasions or refer } \\
\text { to a specialist within one month }\end{array}$ & $\begin{array}{l}\text { Evaluate or refer to source of care } \\
\text { within one week, or, immediately if } \\
\text { the child is symptomatic }\end{array}$ \\
\hline $\begin{array}{l}\text { Therapeutic } \\
\text { lifestyle changes }\end{array}$ & $\begin{array}{l}\text { Weight management counseling if } \\
\text { overweight; introduce physical } \\
\text { activity and diet management }\end{array}$ & $\begin{array}{l}\text { Weight management counseling if } \\
\text { overweight; introduce physical activity } \\
\text { and diet management }\end{array}$ & $\begin{array}{l}\text { Weight management counseling if } \\
\text { overweight; introduce physical } \\
\text { activity and diet management }\end{array}$ \\
\hline $\begin{array}{l}\text { Pharmacologic } \\
\text { therapy }\end{array}$ & $\begin{array}{l}\text { None, unless there are compelling } \\
\text { indications such as chronic kidney } \\
\text { disease, diabetes mellitus, heart } \\
\text { failure, or left ventricular hypertrophy }\end{array}$ & $\begin{array}{l}\text { Initiate therapy if the child has: symptoms } \\
\text { secondary hypertension, hypertensive target } \\
\text { organ injury, diabetes (type I or } 2 \text { ), or } \\
\text { persistent hypertension despite } \\
\text { nonpharmacological measures }\end{array}$ & Initiate therapy \\
\hline
\end{tabular}

Note: *All reference limits are based on gender, age and height for casual BP measurement."

Abbreviation: BP, blood pressure.

also based on ABPM measurement. However, currently there is no consensus of a blood pressure load cutoff value that defines hypertension in children. Because the value of ABPM is increasingly recognized and this method is underutilized, it is further discussed here.

\section{Ambulatory blood pressure monitoring}

ABPM is a tool that offers better sensitivity and specificity in the diagnosis of hypertension. It is becoming a standard of care at many centers offering expertise in pediatric hypertension, and is invaluable in pediatric hypertension research. The monitor can be routinely used in children over five years of age. ${ }^{13}$ ABPM consists of an appropriatesized blood pressure cuff placed on an upper extremity and a monitor worn on a patient's belt. The monitor takes and records blood pressure usually continuously for 24 hours.

Table 3 Classification of blood pressure by ABPM in children and adolescents*

- Normal BP: <90th percentile by ABPM

- Hypertension: $\geq 95$ th percentile by ABPM

-White coat hypertension: Casual $B P \geq 95$ th percentile in medical setting but casual BP or ABPM $\leq 95$ th percentile

- Masked prehypertension: Casual BP $<90$ th percentile in the medical setting but BP at $90-94$ th percentile by casual BP or by ABPM

- Masked hypertension: BP $<90$ th percentile by casual BP in medical setting but $\mathrm{BP} \geq 95$ th percentile by casual $\mathrm{BP}$ or by $\mathrm{ABPM}$

- Blood pressure load: $20 \%-50 \%$ systolic and/or diastolic BP by ABPM values above reference percentile ${ }^{*}$

Notes: *ABPM reference limits; ${ }^{14}{ }^{*}$ no consensus on definition of hypertension based on blood pressure load.

Abbreviations: BP, blood pressure; ABPM, ambulatory blood pressure monitoring.
Typically ABPM records blood pressure every 15-30 minutes during awake hours and every 20-60 minutes during sleep hours, and the data are analyzed in relation to a timed activity diary recorded by the family. ${ }^{13}$ Readings can take place during usual adolescent activities, including going to school, doing homework, eating, and nonvigorous activity, like walking and sleeping. Activities not permitted while on ABPM include vigorous exercise, showering, bathing, and swimming. Commercially available monitors weigh as little as $168-457 \mathrm{~g} .{ }^{13}$ When 24-hour ABPM is used, much richer data are available to the medical evaluator compared with casual blood pressure and self-monitored home blood pressure; these data include the influence of activities on blood pressure, mean 24-hour systolic and diastolic blood pressures, mean awake systolic and diastolic blood pressures, mean sleep systolic and diastolic blood pressures, nocturnal dipping, and blood pressure load. Nocturnal dipping refers to physiological reduction in blood pressure while asleep, and is defined as a percentage: ([mean awake blood pressure - mean sleep blood pressure $] /$ mean awake blood pressure) $\times 100$. Normal nocturnal dipping is defined as $\geq 10 \% .{ }^{15}$ Blood pressure load is defined as the percentage of valid blood pressure measurements above a set threshold value, usually the 95th percentile for age, gender, and height. ${ }^{16}$ Presently, there is no blood pressure load cutoff percentage that defines a normal pediatric population. However, a blood pressure load $>25 \%$ is suggestive of hypertension, while a blood pressure load $>50 \%$ is associated with an increased risk for target organ damage. ${ }^{13}$

Because of the wealth of data provided by ABPM, including the ability to assess nocturnal dip and blood 
pressure load, ABPM is the only reliable study to separate properly patients with sustained hypertension from those with white coat hypertension and to "unmask" masked hypertension in those who have normal casual blood pressure. For example, among 118 children aged 3-19 years with chronic kidney disease, 46 patients were suspected of having hypertension based on casual blood pressure. When ABPM was used, 27 of these 46 patients were diagnosed as having white coat hypertension. ${ }^{17}$ Conversely, ABPM "unmasked" five patients who were deemed to have normal blood pressure by both casual and home self-measured blood pressure, meaning one in five patients diagnosed as hypertensive by ABPM would have been missed even with use of both casual and self-measured blood pressure. ${ }^{17}$

Parallel with adult studies, more recent pediatric ABPM studies have shown a correlation between higher ABPM values and target organ hypertensive changes, including increased left ventricular mass index ${ }^{18,19}$ and increased carotid intima-media thickness, ${ }^{20}$ a known risk factor for stroke in adults. Lastly, ABPM may be a cost-effective tool in pediatric hypertension evaluation because it may eliminate the need for unnecessary studies. One recent pediatric study from a large referral center estimated a saving of \$2.4 million/1000 patients with the use of ABPM in evaluation of elevated blood pressure. ${ }^{21}$

Thus far, ABPM appears to be a very useful tool in blood pressure evaluation and management in the pediatric age group including adolescents, and there are a number of challenges and future study opportunities. These include derivation of normative data in healthy nonwhite populations based on larger data sets, information relating ABPM to welldefined or intermediate end points in youth with sustained hypertension, correlation between treatment efficacy by ABPM measurements and reversal of target organ damage, and evidence-based schema for staging of ABPM levels. ${ }^{13}$ Lastly, a recent report suggests that the process of monitoring blood pressure by ABPM may artificially blunt nocturnal dipping in a study of 103 veterans with chronic kidney disease. ${ }^{22}$ Thus, studies with similar design will need to be performed in children and adolescents to determine whether ABPM itself can induce abnormal nocturnal dipping.

\section{Prevalence of hypertension and target organ damage}

The previous misconception that hypertension is rare in children has been dispelled. Recent epidemiologic data indicate that the prevalence of hypertension has increased from $1 \%$ to $4.5 \%$ over the $1993-2004$ period. ${ }^{1-6}$ In adolescents, the prevalence of hypertension is estimated to be $5 \%$. $3,6,23,24$ An increased awareness and detection of this disorder by pediatricians and school nurses accounts for only a small fraction of this increased prevalence of hypertension. Also, in the past, the association between hypertension and cardiovascular risk occurring during childhood was mostly conjectured or implied. However, more recent studies indicate that arteriolar changes, left ventricular hypertrophy, atherosclerosis, and increased carotid intima-media thickness may be detected in the childhood age group and are no longer limited to the adult population. ${ }^{13,18,25-28}$ Moreover, an increasing number of children present with overt hypertensive symptoms and signs comprising encephalopathy/headache, seizures and congestive heart failure, previously encountered almost exclusively in hypertensive adults.

The prevalence of white coat hypertension in children and adolescents evaluated in the setting of hypertension clinics ranges from $13 \%$ to $88 \% .{ }^{29-31}$ Left ventricular mass index tends to be higher in adolescents with white coat hypertension, ${ }^{32}$ but there are no long-term data on cardiovascular events in this population. ${ }^{30,32}$ Because the prevalence of white coat hypertension may be higher among adolescents who are obese or moderately obese, in the absence of ABPM, white coat hypertension may be grossly underdiagnosed in this relatively large proportion of individuals. Previously, white coat hypertension was thought to be a benign condition, and an artifact of anxiousness when patients are in a health care facility. However, given the recent left ventricular mass index data above and adult data showing other forms of target organ damage associated with white hypertension, ABPM follow-up has been suggested by pediatric hypertension experts. ${ }^{13}$

The prevalence of masked hypertension in normotensive children and adolescents ranges from $7.6 \%$ to $26 \% .^{30,33-35}$ Renal transplant recipients are at even greater risk for developing masked hypertension. ${ }^{36,37}$ However, $40 \%$ of adolescents with masked hypertension have abnormal daytime ABPM on follow-up, and about $10 \%$ go on to develop sustained hypertension and increased left ventricular mass index even prior to developing sustained hypertension. ${ }^{30,33,35,38,39}$ Indeed, the higher risk of target organ injury is much better established with masked hypertension in adults ${ }^{40}$ and in children. ${ }^{33,35}$ At greater risk for such complications are youths with a triad of parental history of hypertension or cardiovascular events, a high resting pulse rate, and high body mass index. ${ }^{33}$ These individuals tend to have an activated sympathetic nervous system. ${ }^{39,40}$

Utilizing strict definitions to classify prehypertension based on blood pressure load in nonobese children with a 
mean age of 9.12 years of age without proteinuria or renal disease, Lubrano et al found that those with blood pressure load $>40 \%$ had a significantly lower glomerular filtration rate and a higher level of proteinuria than control subjects. ${ }^{41}$ It was concluded that children with prehypertension defined at this blood pressure load limit should have renal function and proteinuria measured as an indicator of renal injury related to prehypertension. Other studies have also shown that even mild elevation in blood pressure in children may result in an increased left ventricular mass index and carotid intima-media thickness. ${ }^{25-28}$ Currently, it is not known if lifestyle measures or pharmacotherapy can retard proteinuria, overt renal injury, or other cardiovascular processes. However, the detrimental effect of hypertension on pre-existing chronic kidney disease is well established in children and adults. ${ }^{43-45}$ These effects may correlate better with ABPM than with casual blood pressure measurements. ${ }^{44,46}$ For children and adolescents with chronic kidney disease, proteinuria, and established hypertension, a clear benefit followed the use of intensified intervention with angiotensin-converting enzyme inhibition to achieve mean arterial pressure near the 50th percentile rather than the usual goal of blood pressure $<$ the 90 th percentile. ${ }^{47}$

\section{Primary hypertension}

The older term for primary hypertension was "essential hypertension". This term is no longer used as a synonym for primary hypertension because it incorrectly implies a "normal" or "necessary" process. Despite the rising prevalence of primary hypertension in childhood, secondary hypertension still comprises a much higher proportion compared with adults, $95 \%$ of whom have primary hypertension. ${ }^{48}$ Thus, exclusion of secondary causes of hypertension is particularly important in children presenting with elevated blood pressure. The presence of obesity per se should not be a reason for not considering secondary causes. While there are no absolute differences in the presenting clinical signs and symptoms of these two broad classes of hypertension, there are several general characteristics which may favor a secondary cause (Table 4). Children with secondary causes tend to present with Stage II hypertension and be more symptomatic than those with primary hypertension. A careful medical history, findings on physical examination, and several routine laboratory and imaging studies may provide more clues to implicate secondary hypertension. The reader is also referred to an algorithm that may aid the evaluation of hypertension in children. ${ }^{49}$

Primary hypertension accounts for $48 \%$ to $69 \%$ of children referred for evaluation of hypertension in the US. ${ }^{48,50,51}$
Table 4 General features of children and adolescents suggestive of a secondary cause of hypertension

\section{Medical history}

- Family history of secondary disorders of hypertension, hyperlipidemia, or cardiovascular events in early life

- Use of medications or drugs contributing to hypertension

- Absence of dietary and other lifestyle risk factors for hypertension

- History of renal or cardiovascular disorders

- Absence of sleep disorders

- Urinary tract infections or unexplained fevers in infancy

- Symptoms of hypertension: severe recurrent occipital headache, cardiac decompensation, acute visual disturbances

Physical examination

- Absence of obesity

- Preadolescence

- Stage II hypertension with combined systolic and diastolic BP rise

- Retinal vascular changes

- Higher pulse intensity and BP in upper than in lower extremities

- Low pulse rate and blanched or cool skin

- Periumbilical bruit

- Abdominal mass

- Thyromegaly

- Cutaneous lesions suggestive of specific disorders associated with hypertension, such as tuberous sclerosis, neurofibromatosis, Williams syndrome, Marfan syndrome, Turner syndrome, Cushing syndrome, acanthosis nigricans, skin flushing, pallor, diaphoresis, palpitations

Laboratory studies

- Increased serum creatinine concentration

- Abnormal serum potassium, high calcium, or other electrolyte disorders

- Urinalysis showing pyuria, proteinuria, hematuria, or casts

- Normal or low serum uric acid level (in the absence of renal dysfunction)

- Low C3, and high ANA, double stranded anti-DNA or ANCA titers

- High fasting serum lipids

- Abnormal urinary VMA or HVA excretion or high plasma metanephrines

- Abnormal peripheral plasma renin activity, cortisol, aldosterone, T4, thyroid-stimulating hormone

\section{Imaging studies}

- Renal ultrasound showing asymmetry in kidney size, renal masses, increased echotexture, hydronephrosis; high arterial resistive indices on Doppler study

- Dimercaptosuccinic acid scan showing renal scarring

- Voiding cystorethrography showing vesicoureteral reflux

- Magnetic resonance or computer tomography angiography revealing renal artery stenosis or aortic coarctation

- Echocardiography

- Increased left ventricular mass index; decreased LV function

Abbreviations: ANA, antinuclear antibodies; ANCA, antineutrophil cytoplasmic antibodies; BP, blood pressure; LV, left ventricular; VMA, vanillylmandelic acid; HVA, homovanillic acid.

It has long been known that primary hypertension arises in families. A familial/genetic predisposition to the disorder is supported by population studies in natural-adopted children, parent-offspring relationships, and monozygotic-dizygotic twins. ${ }^{52}$ The disorder is widely believed to have a multifactorial etiology, with both polygenetic and environmental 
contributions. $^{52,53}$ Genetic alterations evolve slowly over millennia and usually provide a survival advantage in response to environmental changes. Hence, genetic influences alone are unlikely to contribute substantially to the three-fold increase in hypertension over the past century ${ }^{5,53}$ or to the much more rapid increase in incidence of hypertension in adults and adolescents over one decade. ${ }^{5}$ Thus, the obesity epidemic and other lifestyle changes offer better explanations for this phenomenon. ${ }^{1-4,6}$ However, despite the strong association between obesity and primary hypertension, obesity per se is not a necessary prerequisite to the development of primary hypertension. Obesity may thus be regarded as a trigger for primary hypertension at any age, by unmasking an underlying, perhaps genetic, predisposition for this disorder. This underscores the need to identify and implement healthy dietary and other lifestyle measures which may lead to prevention of primary hypertension at a young age.

\section{Influence of dietary factors on primary hypertension Sodium/salt}

The link between a high salt intake and hypertension is indisputable. ${ }^{1,53-58}$ Several observational epidemiologic studies, a meta-analysis, ${ }^{58}$ as well as the well designed INTERSALT study, ${ }^{59}$ have confirmed the relationship between salt and hypertension. More importantly, the randomized Dietary Approaches to Stop Hypertension (DASH) study showed that the lower the salt intake the greater the blood pressure reduction in both normotensive and hypertensive individuals on a normal North American diet. ${ }^{60}$

North American children have a high intake of salt, derived mainly from processed food rather than salt added to food by the individual. Sodium restriction is of particular benefit in African-Americans with salt-sensitive hypertension. Figure 1 shows the mechanisms implicated in salt-sensitive hypertension. ${ }^{61}$ Individuals with this disorder have an inheritable impairment in sodium excretion at any level of renal perfusion pressure. This impairment in "pressure natriuresis", combined with an acquired taste for salt leading to ever increasing salt intake, eventually leads to sustained hypertension.

The National High Blood Pressure Education Program recommends a $1.2 \mathrm{~g} /$ day sodium intake for children aged 4-8 years and $1.5 \mathrm{~g} /$ day for older children. ${ }^{11}$ These limits may be difficult to implement. A daily intake of $1.5-2.0 \mathrm{~g}$ of sodium (4.25-5.0 $\mathrm{g}$ of salt) per $\mathrm{m}^{2}$ body surface area may be more realistic because children in North America average a sodium intake double this amount. The DASH diet recommends no added salt, as well as increased fruit and vegetables, as well as low fat and low dairy intake. ${ }^{60}$ This is a more palatable diet and more likely to succeed in the long term.

\section{Potassium/calcium/magnesium}

A higher intake of potassium, calcium and magnesium has been shown to have an ameliorating effect on blood pressure in both experimental models of hypertension, and in human epidemiologic studies. ${ }^{53,56,62}$ No specific requirements for supplemental amounts of potassium, calcium, and magnesium are available for hypertensive children.

\section{Caffeine}

Caffeine may be viewed either as a beverage or as a drug. Currently, it may be among the leading nonprescribed central nervous system stimulant drugs associated with hypertension in adolescents. Its intake has risen in children in North America in parallel with the obesity trend. Many individuals are not aware of the large amounts of caffeine found in many tea products $(70 \mathrm{mg}$ of caffeine per 12 ounces of tea; similar amount per 12 ounces of Mountain Dew $\left.{ }^{\circledR}\right)$. Also, "super-sized" volumes of soft drink beverages may contain high caffeine amounts along with having a high calorie content. Many

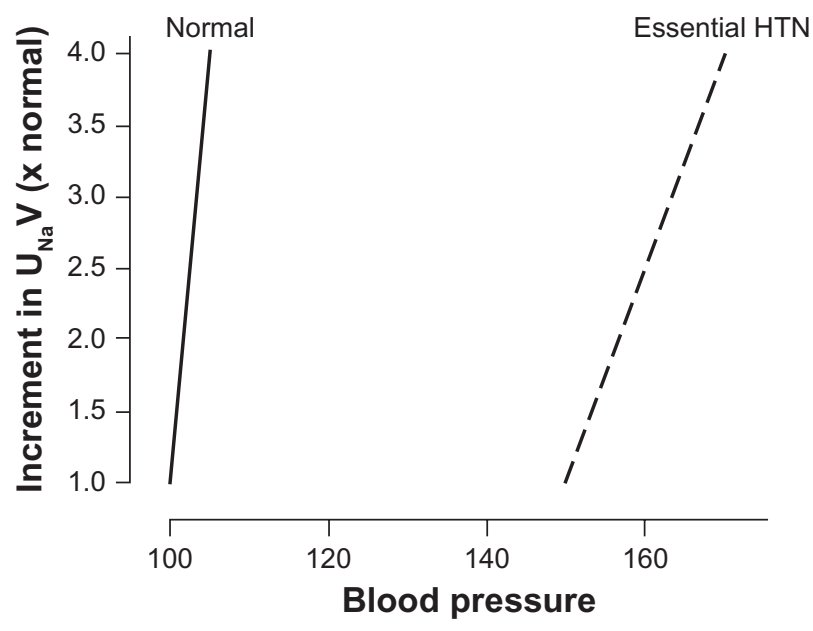

Figure I Mechanism of salt-sensitive hypertension. Under normal conditions, there is a balance between renal perfusion pressure (about $100 \mathrm{mmHg}$ ) and sodium excretion (about $100-120 \mathrm{mmol} /$ day). The increment in arterial pressure is a physiological response directed to promote an increase in urine sodium and water excretion required to bring expanded extracellular fluid volume to normal. Maintenance of hemodynamic homeostasis requires higher blood pressure if the pressure natriuresis mechanism is impaired (shifted to the right and less steep). Copyright@ 9 2007. Elsevier. Adapted with permission from Rodriguez-lturbe B, Romero F, Johnson RJ. Pathophysiological mechanisms of salt-dependent hypertension. Am J Kidney Dis. 2007;4:655-672.61

Abbreviation: $\cup_{\mathrm{Na}} \mathrm{V}$, urinary sodium excretion. 
adolescents are also consuming a large amount of caffeine in the form of "power drinks". Caffeine raises systemic blood pressure by increasing catecholamine release and peripheral vascular resistance. ${ }^{63-65}$ It also increases pulse rate while lowering baroreceptor sensitivity. ${ }^{66,67}$

\section{Fructose}

There is increasing evidence suggesting that fructose consumption $\geq 74 \mathrm{~g}$ per day is associated with a rise in blood pressure in adults and in adolescents. ${ }^{68-70}$ This effect appears to be independent of the link between dietary fructose or sugar-sweetened beverages and the obesity epidemic. ${ }^{71}$ The exact mechanism of fructose-induced hypertension is unknown. Experimental evidence suggests that fructose stimulates the sympathetic nervous system, reduces renal sodium and fluid excretion, and increases serum uric acid levels, which then leads to a direct vascular effect to limit nitric oxide or to activate the renin-angiotensin-aldosterone system. ${ }^{72,73}$

\section{Mechanisms of obesity-related hypertension}

Although significant advances have been made in recent years, the mechanisms mediating obesity-related hypertension are complex and incompletely understood. Several interrelated clinical conditions and multiple mechanisms may act in concert to raise blood pressure. ${ }^{74}$ For example, there appears to be an association between obesity, sleep apnea, and hypertension. The mechanisms can be grouped into sympathetic nervous

Table 5 Mechanisms of obesity-related hypertension

Sympathetic nervous system activation

Renal mechanisms

- Shift of pressure natriuresis towards sodium and fluid retention

- Renal renin-angiotensin-aldosterone system activation

- Renal tissue compression by perirenal fat to induce hyperfiltration

Hormonal abnormalities

- Insulin resistance/hyperinsulinemia

- Hyperleptinemia

- Adipose tissue derived renin-angiotensin-aldosterone system activation

- Aberrant adipokines

Endothelial dysfunction

- Activation of proinflammatory pathways to induce atherosclerotic vascular wall changes

- Reduced vasodilatation due to nitric oxide inactivation and degradation

Note: $*$ This table is a simplified list of mechanisms, and any of these factors are likely to interact to cause hypertension. system activation, renal mechanisms, hormonal abnormalities, and endothelial dysfunction, as shown in Table 5.

Sympathetic nervous system activation in obesity-related primary hypertension has been suggested by a number of epidemiological and clinical data. A meta-analysis by Goldstein showed higher plasma norepinephrine levels in young "essential" hypertensive patients compared with normotensive controls in virtually all studies. ${ }^{75}$ Obese young adults were shown to have marked sympathetic nerve activation compared with aged-matched lean normotensive controls assessed by a microneurographic technique after baroreceptor stimulation and deactivation. ${ }^{76}$ Furthermore, combined $\alpha$ - and $\beta$-adrenergic blockade significantly reduced blood pressure in obese hypertensive patients compared with lean hypertensive controls, again suggesting that increased sympathetic activity is an important factor in obesity-related hypertension. ${ }^{77}$

Several renal mechanisms have been proposed to mediate obesity-related hypertension, including impairment of pressure natriuresis, activation of the renin-angiotensinaldosterone system, and structural changes in the kidney. ${ }^{74}$ As discussed earlier and illustrated in Figure 1, pressure natriuresis is a homeostatic mechanism whereby excess salt and extracellular fluid retention are excreted to reduce venous return and cardiac output until blood pressure normalizes. Conversely, with hypotension, the kidney retains salt and water to increase blood pressure. With obesity, this feedback mechanism appears to shift towards an increase in renal tubular sodium reabsorption. ${ }^{78}$ Although the exact pathophysiology has not been fully elucidated, hyperinsulinemia and insulin resistance, activation of the renin-angiotensin-aldosterone system, and increased sympathetic nervous system activity could all play a role in this impairment. ${ }^{78}$

With obesity, studies have shown activation rather than the expected suppression of the renin-angiotensin-aldosterone system in the setting of sodium retention and extracellular fluid expansion. ${ }^{79,80}$ In one study, individuals with central obesity initially had high plasma levels of peripheral renin activity, aldosterone, and angiotensin-converting enzyme, which improved within six months of gastric bypass surgery. ${ }^{79}$ There appears to be both renal renin-angiotensinaldosterone system activation and adipose tissue production of renin-angiotensin-aldosterone system hormones. Renal renin-angiotensin-aldosterone system activation appears to occur via compression of the kidney by perirenal fat that elevates interstitial fluid hydrostatic pressure, leading to reduced medullary blood flow. ${ }^{81}$ This results in decreased 
sodium detection by the macula densa, leading to increased renin secretion, and elevation of blood pressure occurs via angiotensin II-induced systemic vasoconstriction, direct sodium and water retention, and increased aldosterone production. $^{74}$

In addition to physical compression of the kidneys leading to activation of the renal renin-angiotensin-aldosterone system, perirenal fat can change the physical structure of the kidneys, leading to hyperfiltration, which, over time, induces glomerular sclerosis and nephron loss, ${ }^{74}$ ultimately leading to inappropriate alteration in pressure natriuresis and activation of the renin-angiotensin-aldosterone system.

There are a number of additional hormonal abnormalities associated with obesity which are potentially connected with elevation of blood pressure. Hyperinsulinemia, as a consequence of insulin resistance, has been linked with hypertension mediated by its antinatriuretic effects, enhanced sympathetic nervous system activity, augmented responses to endogenous vasoconstrictors, altered vascular membrane cation transport, impaired endothelium-dependent vasodilatation, and stimulation of vascular smooth muscle growth. ${ }^{82}$ Adipose tissue is increasingly recognized as an endocrine organ, with at least 50 different substances now identified, and many are implicated in blood pressure control. ${ }^{82}$ Leptin is primarily secreted by adipose tissue, and its circulating levels parallel fat cell mass. Its main role is to control food intake and energy expenditure. ${ }^{83}$ It acts on receptors in the hypothalamus to regulate energy balance by decreasing appetite and increasing energy expenditure through sympathetic stimulation. ${ }^{84}$ Animal studies indicate that long-term infusion of leptin raised blood pressure and pulse rate, and these increases were abolished after combined $\alpha$ - and $\beta$-adrenergic blockade. ${ }^{84}$ Finally, there are adipocytederived peptides, collectively termed adipokines, that may also affect blood pressure. One such peptide, adiponectin, protects against hypertension via endothelial-dependent vasodilatation, and its level falls in obesity-induced insulin resistance. ${ }^{82}$ In addition, another adipokine, resistin, has been found to have a positive correlation with elevated blood pressure. $^{82}$

Finally, dysfunction in vascular endothelium leading to changes in systemic vascular resistance is another major mechanism of hypertension. There is a growing recognition that obesity represents a state of chronic, low-grade inflammation leading to various proinflammatory pathways, including cytokines interacting with adipokines, leading to atherosclerotic vascular wall changes and reduction in endothelium-dependent relaxation. ${ }^{85}$ In addition, obesity contributes to increased oxidative stress and superoxide production, which are associated with nitric oxide inactivation and degradation in the vessel wall, leading to reduced vasodilatation. ${ }^{85}$

\section{Management of primary hypertension Lifestyle and nonpharmacologic measures}

Regardless of the etiology of hypertension, pediatricians and other health care providers must inquire about environmental risk factors that may influence blood pressure, and must also obtain a detailed family history in order to assess genetic risk. Intervention should start at the prehypertensive stage after identifying risk factors, including overweight, sleep disorders, exogenous substances that may provoke hypertension, excessive participation in video-computer games, and assessment of psychosocial factors that may affect stress at home and at school. Attention must be given to the sodium content of processed food, the amount of fat in the diet, and the amount of vegetables and fruit consumed by the patient. An overview of the amount and type of exercise are an essential part of the medical history. The following is a summary of evidence for lifestyle modification to improve blood pressure.

Because much of the elevated blood pressure in primary hypertension is attributed to obesity and sodium retention, current dietary strategies to lower blood pressure are aimed at reducing sodium intake and body weight. Reducing dietary sodium lessens the demand on the kidneys to excrete enough sodium to restore normal blood volume. ${ }^{86}$ Weight loss will also lead to reversal of the pathophysiological pathways of obesity and hypertension discussed earlier. The most established dietary patterns are the DASH diet, ${ }^{87}$ variations of the DASH diet, and variations of the Mediterranean diet. In the original DASH diet trial, 459 adults aged 22 years and older with systolic blood pressure $<160 \mathrm{mmHg}$ and diastolic blood pressure $80-95 \mathrm{mmHg}$, were randomly assigned to receive eight weeks of the control diet, a diet rich in fruit and vegetables, or a "combination" diet rich in fruit, vegetables, and low fat dairy products and with reduced saturated and total fat, while sodium intake and body weight were maintained at constant levels. Among the 133 subjects with systolic blood pressure $\geq 140 \mathrm{mmHg}$ or diastolic blood pressure $\geq 90 \mathrm{mmHg}$, the combination diet (later termed the DASH diet) reduced systolic and diastolic blood pressure by $11.4 \mathrm{mmHg}$ and $5.5 \mathrm{mmHg}$ more than the control diet, respectively. ${ }^{87}$ In the subsequent trial with similar participants and the same ages, 412 participants were randomly assigned to either a control diet typical of intake in the US, 
or the DASH diet with three different levels of sodium, for 30 consecutive days each, in random order. ${ }^{60}$ The effects of sodium were observed in participants with and without hypertension, in all races and both genders. The DASH diet was associated with a significantly lower systolic blood pressure at each sodium level. As compared with the control diet with a high sodium level, the DASH diet with a low sodium level led to a mean systolic blood pressure of $7.1 \mathrm{mmHg}$ lower in participants without hypertension, and $11.5 \mathrm{mmHg}$ lower in participants with hypertension. ${ }^{60}$ Similar interventions and results for adolescents have also been published. Fifty-seven adolescents, aged 11-18 years with prehypertension or Stage I hypertension were randomly assigned to clinic-based behavioral nutrition intervention using either the DASH diet or routine outpatient hospital-based nutrition care for three months, and then had a follow-up assessment three months after completion of treatment. Systolic blood pressure Z-score showed a statistically significant decline at post-treatment and a near statistically significant $(P=0.07)$ decline at the three-month post-intervention follow-up. ${ }^{54}$

On the other hand, studies have also shown a reduction in blood pressure with increased level of activity. The relationship has been clearly established in adults, including those with obesity. ${ }^{88}$ This relationship appears to be intact in the pediatric age range, ${ }^{89}$ and the improvement in blood pressure appears to correlate with improvement or reversal of target organ damage. A three-month randomized controlled trial in 44 prepubertal obese children and 22 lean children showed significant reductions in systolic and diastolic blood pressures, rates of hypertension, office blood pressure, body mass index Z-score, abdominal fat, and maximal oxygen uptake. ${ }^{90}$ These improvements correlated with significant improvements in arterial stiffness and arterial intima-media thickness at six months after the start of intervention. Another recent study of subjects aged 5-17 years showed significant improvements in 24-hour ABPM and other cardiovascular clinical outcomes, including left ventricular mass index, prevalence of left ventricular hypertrophy, and carotid intima-media thickness, after 12 months of nonpharmacological and pharmacological therapy ( 37 of 86 subjects in the study received nonpharmacological therapy, including diet modification and increase in physical activity). ${ }^{91}$ A literature review on obesity, physical activity, and blood pressure recommends 40 minutes of moderate to vigorous aerobic-based physical activity $3-5$ days per week to reduce blood pressure in obese children. ${ }^{89}$

Based on the aforementioned data, lifestyle changes are an integral part in managing all children with prehypertension
Table 6 Lifestyle modifications and approximate range of systolic blood pressure reduction*

- Exercise/limit television and other sedentary activities $(4-9 \mathrm{mmHg})$

- Weight reduction (smaller portions/exercise) $(5-20 \mathrm{mmHg} / 10 \mathrm{~kg}$ weight loss)

- Consume more fresh vegetables and fruits, low fat dairy products and low content of saturated fats $(2-8 \mathrm{mmHg})$

- Reduce sodium intake $(2-8 \mathrm{mmHg})$

- Avoid alcohol (2-4 mmHg)

- Limit caffeine

- Avoid tobacco (cigarettes/chewing)

Note: *Obtained from adult studies.

or hypertension. The estimated blood pressure-lowering effect in mmHg obtained by implementing several common lifestyle measures is shown in Table 6. A conservative nonpharmacologic approach may also serve as the only initial intervention in children with Stage I hypertension without target organ injury. The aim of treatment is not only to lower blood pressure, but also to limit the other consequences of an unhealthy lifestyle which may impact long-term cardiovascular morbidity and mortality. Apart from reducing calories in the overweight and obese, and controlling hyperlipidemia, a reduction in salt and caffeine intake is appropriate. A balance of calorie intake and exercise is essential. Sleep disorders may require special evaluation and management. Counseling on the health consequences of drug, alcohol, and tobacco use should be reinforced at all office or clinic visits. It is essential that education and counseling be provided to the entire family and not just the child so as to enhance motivation and compliance with the proposed treatment plan.

Setting realistic and measurable goals over specified periods of time for achieving weight reduction, correction of metabolic disturbances, and numerical targets of blood pressure, are useful adjuncts in managing the hypertensive child.

\section{Pharmacologic management of primary hypertension}

The reader is referred elsewhere for a more comprehensive review of the pharmacologic treatment of pediatric hypertension. ${ }^{92}$ There are no large, longitudinal studies to provide evidence-based guidelines for the management of primary hypertension in children. ${ }^{93}$ Agents may be chosen based on unwanted side effects tailored to the individual child's activities and habits. For example, because $\beta$-blockers may inhibit reflex tachycardia in children involved in vigorous activities, such agents may cause syncope and other adverse cardiovascular events. Thus, unlike guidelines for managing 
primary hypertension in adults, ${ }^{7}$ diuretics and $\beta$-blockers are rarely employed as initial agents in the control of primary hypertension in children. Close monitoring of blood pressure is essential in modifying the dosages of antihypertensive agents, especially in children with primary hypertension, in whom improvements in lifestyle may have a dramatic effect in lowering blood pressure.

The combined use of a $\beta$-blocker and a thiazide was associated with suboptimal blood pressure control in one pediatric study of primary hypertension. ${ }^{94}$ However, hypertensive adolescents with a triad of parental history of hypertension or cardiovascular events, a high resting pulse rate, and high body mass index, may benefit from such pharmacotherapy to reduce blood pressure, particularly if lifestyle measures fail to accomplish this goal after a reasonable period of time, such as $6-12$ months. In children with tachycardia and isolated systolic hypertension, noncardioselective $\beta$-blockers, such as carvedilol, may be more efficacious, and have fewer adverse effects on lipid and glucose metabolism than the more cardioselective $\beta$-blockers, such as atenolol and metoprolol. Thus, use of carvedilol may be advantageous in children with hypertension who are obese and prone to metabolic syndrome.

The use of calcium channel blockers and angiotensinconverting enzyme inhibitors was examined in a retrospective study of primary hypertension in childhood. ${ }^{95}$ Both classes of agents lowered systolic blood pressure, but only angiotensinconverting enzyme inhibitors also lowered diastolic blood pressure. However, when blood pressure below the 95th percentile for age, gender, and height was the "target value", only $45 \%$ achieved systolic blood pressure control, while $62.7 \%$ achieved diastolic blood pressure control. ${ }^{95}$

Angiotensin-converting enzyme inhibitors have been shown to be as effective as $\beta$-blockers and diuretics in adults with primary hypertension. Angiotensin-converting enzyme inhibitors may also have greater cardioprotective benefits which extend beyond blood pressure-lowering, whereas several studies indicate an increase in coronary artery disease and heart failure with use of calcium channel blockers. Although such adverse outcomes are uncommon in children managed with calcium channel blockers, the authors generally prefer starting with an angiotensin-converting enzyme inhibitor or angiotensin receptor blocker for pharmacologic management of primary hypertension in children and adolescents.

Important outcome measures of managing primary hypertension in adults include a reduction in coronary heart disease, stroke, and cardiovascular death. No such data are available in children.

\section{Goals and general principles of hypertension therapy}

In asymptomatic children, the National High Blood Pressure Education Program ${ }^{11}$ recommends achieving target blood pressure below the 95th percentile if there is no other coexisting disorder, and below the 90th percentile in children with evidence of coexisting cardiovascular risk factors, diabetes, or target organ damage. Hypertension in children with overt proteinuria or progressive renal insufficiency is also an indication for lowering blood pressure to below the 90th percentile.

Of immediate concern is the management of acute symptoms of hypertension. For example, aggressive and immediate pharmacologic control of blood pressure is often required in hypertensive children with overt evidence of target organ injury in the form of encephalopathy, seizures, Bell's palsy, cerebrovascular accident, congestive heart failure, or hypertensive retinopathy.

The long-term objective of hypertension control is the prevention of cardiovascular disease and heart failure, which remain the leading causes of morbidity and mortality among adults in the US. Currently there are no longitudinal studies in children assessing the relationship of the level and duration of hypertension and cardiovascular risk. While numerical goals are often used to assess the efficacy of therapy, isolated blood pressure values obtained at clinic settings may be unreliable. Thus, many experts recommend more reliable means of predicting cardiovascular complications, including ABPM. ${ }^{13,96,97}$

Reversal of the symptoms and signs of hypertension and target organ changes is an even more important goal of therapy. Left ventricular hypertrophy on echocardiography is perhaps the most sensitive means for detecting target organ injury in children with well established hypertension. Left ventricular hypertrophy is detected in $40 \%$ of such children. ${ }^{18,27,97}$ Microalbuminuria, as a marker of microvascular disease, is another early clinical indicator of target organ damage in adults with hypertension, but its importance has not been investigated in children, except in those with type 1 diabetes.

\section{Drug-induced hypertension}

Hypertension in response to normal use of prescribed medications, abuse of prescribed or over-the-counter medications, or use of illicit or illegal drugs, is an important cause of secondary hypertension. Hypertension may occur with any of the agents listed in Table 7. Also, a genetic predisposition to hypertension may be unmasked while preexisting hypertension may be exacerbated by use of these 
Table 7 Partial list of exogenous substances that raise blood pressure

\begin{tabular}{|c|c|c|c|}
\hline Substance & Raise BP & $\begin{array}{l}\text { Interfere } \\
\text { with therapy }\end{array}$ & $\begin{array}{l}\text { Source of } \\
\text { substance }\end{array}$ \\
\hline Anabolic steroids & Yes & No & Patient \\
\hline Caffeine & Yes & No & Patient \\
\hline Cocaine & Yes & Yes & Patient \\
\hline Ethanol & Yes & No & Patient \\
\hline Ephedra & Yes & Yes & Patient \\
\hline Nicotine & Yes & No & Patient \\
\hline Sodium chloride & Yes & Yes & Patient \\
\hline $\begin{array}{l}\text { Sympathomimetic } \\
\text { agents }\end{array}$ & Yes & No & $\begin{array}{l}\text { Patient or } \\
\text { clinician }\end{array}$ \\
\hline $\begin{array}{l}\text { Nonsteroidal anti- } \\
\text { inflammatory agents }\end{array}$ & Yes & Yes & $\begin{array}{l}\text { Patient or } \\
\text { clinician }\end{array}$ \\
\hline Chlorpromazine & Yes & No & Clinician \\
\hline Corticosteroids & Yes & Yes & Clinician \\
\hline Cyclosporine & Yes & No & Clinician \\
\hline Tacrolimus & Yes & No & Clinician \\
\hline Erythropoietin & Yes & No & Clinician \\
\hline $\begin{array}{l}\text { Monoamine oxidase } \\
\text { inhibitors }\end{array}$ & Yes & No & Clinician \\
\hline Oral contraceptives & Yes & No & Clinician \\
\hline $\begin{array}{l}\text { Tricyclic } \\
\text { antidepressants }\end{array}$ & Yes & No & Clinician \\
\hline Strattera ${ }^{\circledR}$ & Yes & No & Clinician \\
\hline Concerta $^{\circledR}$ & Yes & No & Clinician \\
\hline Adderal ${ }^{\circledast}$ & Yes & No & Clinician \\
\hline Wellbutrin ${ }^{\circledR}$ & Yes & No & Clinician \\
\hline Ritalin $^{\circledR}$ & Yes & Yes & Clinician \\
\hline Dexedrine $^{\circledR}$ & Yes & Yes & $\begin{array}{l}\text { Patient or } \\
\text { Clinician }\end{array}$ \\
\hline Ecstasy & Yes & Yes & Patient \\
\hline$\beta$-adrenergic agonists & Yes & Yes & Clinician \\
\hline Theophylline & Yes & No & Clinician \\
\hline Phencyclidine & Yes & No & Clinician \\
\hline
\end{tabular}

Abbreviation: BP, blood pressure.

agents. Moreover, coadministration of these substances may lead to accelerated hypertension.

Among prescribed medications, corticosteroids, such as prednisone, used in the management of many autoimmune and inflammatory disorders, asthma and other pulmonary disorders, and to prevent rejection after transplantation, lead the list of drugs that cause hypertension..$^{98}$ Mechanisms for steroid-induced hypertension include a direct mineralocorticoid action and suppression of the kallikrein-kinin system, resulting in enhanced sensitivity to endogenous vasoconstrictors and mineralocorticoids, ${ }^{99}$ and stimulation of angiotensin II type I receptors, resulting in increased sodium and fluid retention, and increased cardiac output and total peripheral resistance. ${ }^{100}$ Calcineurin inhibitors, such as cyclosporine and tacrolimus, are also utilized for the treatment of several of these disorders. The mechanisms of hypertension associated with calcineurin inhibitors include vasoconstriction of the afferent glomerular arteriole through stimulation of the sympathetic nervous system, and local release of endothelin-1, resulting in renin release and angiotensin II/aldosterone-mediated systemic hypertension. ${ }^{101,102}$

Increasing numbers of adolescents are receiving oral contraceptive agents to manage dysmenorrhea or for birth control purposes. Depending on the estrogen content and interplay of dietary and genetic risk factors, or interaction with other drugs and vasoactive substances, such adolescents may develop symptomatic or asymptomatic hypertension. The pathophysiology of estrogen-induced hypertension involves stimulation in the renin-angiotensin-aldosterone system and ensuing sodium and fluid retention. ${ }^{103}$ Nonsteroidal antiinflammatory drugs may cause hypertension by suppressing the synthesis of several important renal prostaglandins which facilitate sodium and fluid excretion as well as vasodilation. ${ }^{104}$

Another group of legal substances that are currently abused on a large scale by adolescents are stimulants containing dextroamphetamine, found in numerous cough/ cold/nasal decongestant and asthma medications. According to the 2009 Monitoring the Future survey sponsored by the National Institute of Drug Abuse, nearly 6\% of all youth in the 10th and 12th grades had abused such drugs over the preceding year (www.drugabuse.gov). These over-the-counter medications are readily available and relatively inexpensive. They are used recreationally and produce a state of euphoria or "high". Dextroamphetamine is also found in Dexedrine ${ }^{\circledR}$ and Aderall ${ }^{\circledR}$, while methylphenidate, which has a similar effect, is found in Ritalin ${ }^{\mathbb{R}}$ and Concerta ${ }^{\circledR}$. Dextroamphetamine can also be purchased in bulk powder over the Internet. While their prescribed use is safe and effective, when abused, these agents raise brain norepinephrine and dopamine concentrations, and also result in systemic tachycardia, vasoconstriction, and hypertension. Similarly, illicit drugs, such as ecstasy (3,4 methylenedioxymethamphetamine), monoamine oxidase inhibitors, such as tranylcypromine and other antidepressants, and cocaine may cause acute hypertension by stimulation of $\alpha$-adrenergic action (catecholamine release), resulting in acute tachycardia and vasoconstriction. ${ }^{105}$ Hypertension in individuals with cocaine intoxication or monoamine oxidase inhibitor crisis may be controlled by $\alpha$-adrenergic blockers while avoiding the initial use of $\beta$-blockers which may potentiate the $\alpha$-adrenergic action of catecholamines. Cocaine may also cause hypertension through chronic kidney injury. ${ }^{106}$ Despite being banned by the US Food and Drug Administration, children and adolescents illegally use central 
nervous stimulants containing ephedra or ephedrine or a similar stimulant, bitter orange. These children are at risk for hypertension through catecholamine release and stimulation of $\alpha$-, $\beta 1$-, and $\beta 2$-adrenergic receptors. ${ }^{106}$

Other commonly prescribed drugs include erythropoietin, used to manage anemia associated with chronic renal failure and other disorders. Apart from increasing hematocrit, erythropoietin increases sensitivity to endogenous vasopressors, and may have a direct vasopressor and trophic effect on vessels. ${ }^{107,108}$

Although there are legitimate beneficial effects of anabolic steroids in cancer and other patients, these agents are often used inappropriately for nonmedical purposes, such as muscle building and for enhancing general athletic performance. These may cause hypertension through their testosterone-like effects.

Among dietary and herbal stimulants, the influence of caffeine in inducing hypertension has already been discussed. Large amounts of caffeine are responsible for the stimulating effect of many popular "energy drinks" such as Nitric Oxide System ${ }^{\circledR}$, 5-Hour Energy ${ }^{\circledR}$, Battery Energy Shot ${ }^{\circledR}$, and Cocaine ${ }^{\circledR}$. The herbal extract, yohimbine, is often used as an aid to erectile dysfunction and an aid to weight loss. It is also a stimulant that raises plasma norepinephrine levels while lowering presynaptic $\alpha_{2}$-adrenergic blockade, leading to tachycardia and hypertension. ${ }^{109}$

According to the 2009 Monitoring the Future survey, alcohol and cigarette use are by far the most common habits among adolescents. Among high school seniors, 36.5\% had used an illicit drug during the preceding year, $4.7 \%$ had used cocaine or crack cocaine, and $5.5 \%$ had used ecstasy or methamphetamines over the preceding year, while $5.2 \%$ had used marijuana on a daily basis. These trends have been relatively unchanged over the past five years.

Ethanol induces hypertension by blunting the blood pressure response of plasma renin activity to changes in sodium intake. ${ }^{110}$ Chronic tobacco use has several detrimental effects on the vascular endothelium and arterial wall thickening, resulting in decreased vasodilation and increased total peripheral resistance and hypertension. ${ }^{111,112}$

\section{Pregnancy-associated hypertension}

Approximately 750,000 women younger than 20 years of age become pregnant in the US each year. The estimated teenage pregnancy rate in 2006 was 71.5 per 1000 women aged $15-19$ years, or $7 \%$ of this age group ${ }^{113} \mathrm{New}$-onset hypertension may occur in up to $8 \%$ of pregnancies. ${ }^{114,115}$ Adolescents have a significant higher risk for pregnancy-associated hypertension and for having small for gestational age offspring who may also be susceptible to hypertension. Gestational hypertension in adolescents may also be a forerunner to development of sustained maternal hypertension 6-9 years after pregnancy.

The spectrum of hypertension during pregnancy includes pre-eclampsia (more common, associated with proteinuria), eclampsia (less common, associated with proteinuria and seizures), and gestational hypertension (no proteinuria).

The incidence of pre-eclampsia has risen by $40 \%$ in the past $10-20$ years. ${ }^{15,116}$ The condition typically presents with proteinuria, edema, headache, emesis, abdominal pain, and visual disturbances after 20 weeks of pregnancy. Risk factors for the disorder include obesity, a large gap between pregnancies, multiparity, and teenage pregnancy. Also, pre-eclampsia during a previous pregnancy increases the subsequent risk from $3.3 \%$ to $20 \%$. Pre-existing hypertension and renal disease are important risk factors in 30\% of women who develop pre-eclampsia. Moreover, 20\% of women with eclampsia will go on to develop sustained systemic hypertension after pregnancy.

The pathogenesis of pre-eclampsia and its more serious form, eclampsia, is partly elucidated. According to the leading hypothesis, a reduction in uteroplacental blood flow related to abnormal arterioles in the cytotrophoblast may initiate placental ischemia. This then leads to synthesis and release of proangiogenic factors and vasoactive substances which favor aberrant local and systemic vasoconstriction rather than the physiologic vasodilation and blood volume expansion observed during normal pregnancy. Elevated plasma concentrations of vasocontrictive thromboxane and endothelin-1 and reduction in vasodilatory prostaglandins and nitric oxide have been found in this disorder. ${ }^{116,117}$ Also, there is an increase in proinflammatory cytokines, tumor necrosis factor- $\alpha$, and interleukins 1 and 6 , which stimulate endothelin synthesis but reduce acetylcholine-mediated vasodilation, all of which favor the development of hypertension. ${ }^{118-121}$

Experimental evidence also implicates prolonged inhibition of nitric oxide synthase in the pathogenesis of eclampsia-associated hypertension. ${ }^{122,123}$ This leads to loss of modulation of vasoconstrictor substances, resulting in renal and systemic vasoconstriction, proteinuria, intrauterine growth retardation, and high fetal morbidity, similar to that encountered in humans with this disorder.

A rare and intriguing monogenic disorder predisposing to pre-eclampsia and eclampsia has also been described with a gain of function mutation of the mineralocorticoid receptor of the principal renal tubular cells. ${ }^{124}$ This mutant receptor is activated by the high plasma concentrations of progesterone 
prevailing during pregnancy, thereby resulting in pathologic increases in sodium retention, volume expansion, and hypertension. Because spironolactone inhibits the wild-type mineralocorticoid receptor, but tends to activate the mutant receptor, this agent may promote rather than reduce blood pressure in this disorder.

Although pre-eclampsia usually resolves after delivery of the infant and placenta, it is desirable to manage the hypertension until at least 32 weeks of gestation so as to limit the complications of prematurity to the fetus. Provided there is no target organ damage, as a general rule, a higher threshold for treatment may be used (usually diastolic blood pressure $>100 \mathrm{mmHg}$ and/or systolic blood pressure $>160 \mathrm{mmHg}$ ), because lower placental blood flow may compromise growth and overall safety of the infant. The goal of therapy is a diastolic blood pressure below $90 \mathrm{mmHg}$. Drugs that do not affect placental blood flow are recommended. ${ }^{125}$ Alpha-methyldopa may be an initial agent, and hydralazine is another such agent. Angiotensin-converting enzyme inhibitors and angiotensin receptor blockers should not be use to manage pregnancy-associated hypertension because of teratogenic events noted as early as the first trimester of pregnancy that was previously thought to be a safe period. ${ }^{126}$ Birth defects include cardiovascular and neurologic complications, craniofacial deformities, and renal dysplasia, leading to renal insufficiency and oligohydramnios.

In individuals nearing delivery, prophylaxis against seizures (eclampsia) is essential during labor and for 1-2 days after delivery. This consists of intravenous magnesium sulfate, starting with a $4 \mathrm{~g}$ loading dose (over 15-20 minutes), followed by $2 \mathrm{~g}$ per hour by continuous infusion thereafter. The goal is to achieve high $(6 \mathrm{mg} / \mathrm{dL})$ but nontoxic blood magnesium levels.

\section{Video/computer games and blood pressure}

A telephone survey published in 2004 found a mean daily video game usage of 1.1 hours and computer game usage of 0.54 hours in children younger than 11 years. ${ }^{127}$ In a similar study, 8-18-year-olds played an average of 1.21 hours of video games per day, and the average time was even longer in boys, at 1.61 hours per day. ${ }^{128}$ Recent investigations have linked cardiovascular responses to acute stressors, including video game playing, with both immediate and future blood pressure elevation. Among 88 healthy youngsters aged 7-13 years, born to at least one parent with primary hypertension, elevated systolic blood pressure responses to an acute stress from five minutes of video game playing was predictive of higher systolic blood pressure by ABPM 2.5 years later. ${ }^{129}$ A recent report in healthy German boys aged 12-14 years, using more updated video games with complicated controllers, demonstrated systolic and diastolic blood pressures rise exceeding two standard deviations in 14 of 17 subjects during 12 minutes of playing. ${ }^{130}$ Further, this study also found similar systolic and higher diastolic blood pressures, despite less energy consumption during video game playing compared with riding a bicycle ergometer. ${ }^{130}$ Thus, these studies suggest that video game playing not only contributes to a more sedentary lifestyle with less energy consumption, but it also intrinsically elevates blood pressure acutely, and may lead to development of sustained elevated blood pressure in the long run. Finally, a recent study in 25 boys and 23 girls aged 13-16 years reported that the systolic blood pressure response while preparing and giving speeches was independently predictive of carotid intima-media thickness. ${ }^{131}$ Although we are unaware of any study linking video game playing with hypertensionrelated target organ changes, based on the above studies, one may postulate that individuals involved in extended and habitual video game playing may be exposed to recurrent excitement and acute stress responses that may potentially lead to hypertension-related target organ damage.

\section{Hypertension in athletes}

Systemic hypertension is the most common cardiovascular condition observed in competitive athletes, ${ }^{132}$ many of whom are adolescents. Almost $80 \%$ of adolescent athletes with blood pressure $<142 / 92 \mathrm{mmHg}$ during sports preseason screening examination eventually developed sustained hypertension. ${ }^{133}$ Unique to conditioned athletes are two phenomena that can lead to isolated systolic hypertension. Foremost is the fact that the "athlete's heart" is characterized by a high resting stroke volume and cardiac output, and low peripheral resistance and heart rate. ${ }^{134}$ These individuals may have a high pulse pressure and systolic blood pressure, often in the range of prehypertension, and occasionally in the range of Stage I hypertension, while diastolic blood pressure is in the normal range due to a higher resting stroke volume and cardiac output. ${ }^{135}$ The other phenomenon is spurious systolic hypertension, felt to result from exaggerated pulse pressure amplification in the arm. ${ }^{136}$ The latter occurs as a result of the progressive decrease in arterial diameter from the heart to the arm and the corresponding increase in arterial impedance, resulting in aortic systolic pressure being normal and up to $30-40 \mathrm{mmHg}$ lower than brachial systolic pressure. Although the long-term cardiovascular significance of this is unknown, it may reflect greater stoke volume in athletes. ${ }^{136}$ 
The American Academy of Pediatrics recently released a policy statement regarding athletic participation by children and adolescents with hypertension. ${ }^{137}$ Regular exercise has been shown to help reduce both systolic and diastolic blood pressure, thus regular physical activity is encouraged in those with hypertension. ${ }^{11}$ However, given reports of cerebrovascular accidents during maximal exercise, the American Academy of Pediatrics policy recommends temporary activity restriction for athletes who have Stage II hypertension until normal blood pressure is achieved. ${ }^{137}$

There are two classes of exercises which may affect blood pressure differently. Dynamic exercise involves changes in muscle length and joint movement, with rhythmic contractions that develop relatively small intramuscular force. In contrast, static exercise involves development of relatively large intramuscular force with little or no change in muscle

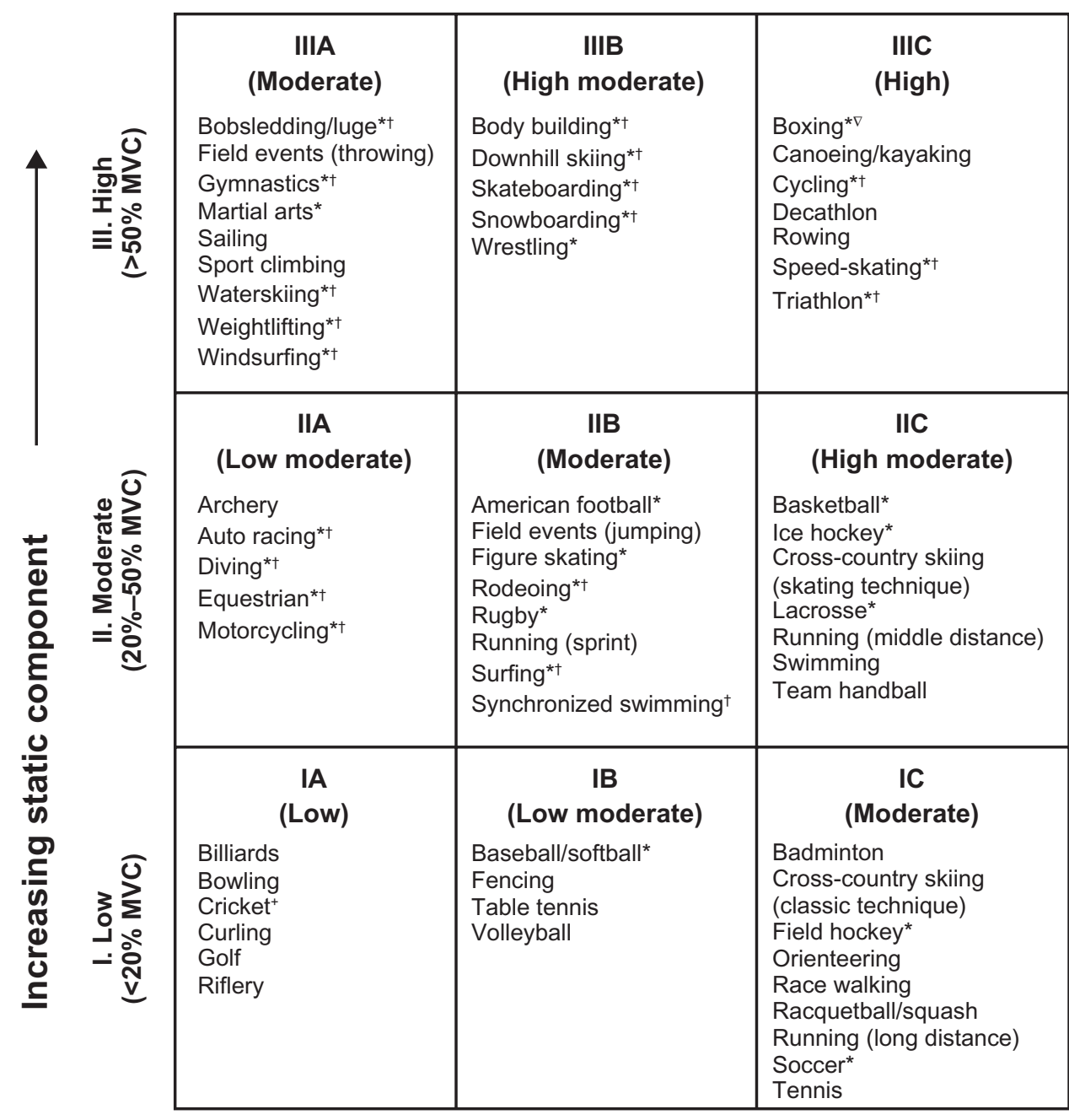

$\begin{array}{ccc}\text { A. Low } & \text { B. Moderate } & \text { C. High } \\ \left(<40 \% \max \mathrm{O}_{2}\right) & \left(40 \%-70 \% \max \mathrm{O}_{2}\right) & \left(>70 \% \max \mathrm{O}_{2}\right)\end{array}$

Increasing dynamic component

Figure 2 Classification of sports according to cardiovascular demands (based on combined static and dynamic components). This classification is based on peak static and dynamic components achieved during competition. However, it should be noted that higher values may be reached during training. The increasing dynamic component is defined in terms of the estimated percent of maximal oxygen uptake achieved, and results in an increasing cardiac output. The increasing static component is related to the estimated percent of MVC reached and results in an increasing blood pressure load. The lowest total cardiovascular demands (cardiac output and blood pressure) are shown in Box IA and the highest are shown in Box IIIC. Boxes IIA, IB, IIIA, IIB, IC, IIIB and IIC depict low-moderate, moderate, and high-moderate total cardiovascular demands. These categories progress diagonally across the table from lower left to upper right.

Notes: *Danger of bodily collision; ${ }^{\dagger}$ Increased risk if syncope occurs; ${ }^{\nabla}$ Participation not recommended by the American Academy of Pediatrics; ${ }^{+}$The American Academy of Pediatrics classifies cricket in the IB box (low static, moderate dynamic).

Copyright@ 20I0. Elsevier. Adapted with permission from McCambridge TM, Benjamin HJ, Brenner JS, et al. Athletic participation by children and adolescents who have systemic hypertension. Pediatrics. 2010;125:1287-1294. ${ }^{137}$

Abbreviations: HTN, hypertension; MVC, maximal voluntary contraction. 
length or joint movement. ${ }^{138}$ Most physical activities involve both dynamic and static components to varying degrees. For example, long distance running has high dynamic and low static components, weight lifting has low dynamic and high static components, and boxing has both high dynamic and static components. Dynamic exercise causes a marked increase in oxygen consumption, cardiac output, heart rate, stroke volume, and systolic blood pressure, as well as a moderate increase in mean arterial pressure and a decrease in diastolic blood pressure and total peripheral resistance. In contrast, static exercise causes a small increase in oxygen consumption, cardiac output, and heart rate, with no change in stroke volume, a marked increase in systolic and diastolic blood pressure and mean arterial pressure, and no appreciable change in total peripheral resistance. ${ }^{138}$ The concern with static exercise is the acute increase in diastolic blood pressure and possible increase in muscle mass that may elevate resting blood pressure. Thus, the expert opinion is to be more cautious in athletes with Stage II hypertension who participate in more static exercise, although limited evidence show no greater risk with highly static exercise. ${ }^{137}$

Figure 2 shows various sports classified according to cardiovascular demands. The American Academy of Pediatrics recommendations include no limitation of competitive athletics for youths with prehypertension or Stage I hypertension in the absence of end organ damage, including left ventricular hypertrophy or concomitant heart disease. For youths with Stage II hypertension without end organ damage, the American Academy of Pediatrics recommends restrictions on highly static sports (classes IIIA and IIIC in Figure 2) until their blood pressure normalizes after therapy. ${ }^{137}$

When evaluating adolescent athletes for hypertension, particular attention should be paid to not only their diet and activity, but to other potential behavioral contributors to elevated blood pressure, including use of alcohol, caffeine, drugs (cocaine and stimulants), tobacco, nonsteroidal anti-inflammatory drugs, human growth hormone, erythropoietin, anabolic steroids, diet pills, and herbal supplements. ${ }^{136}$ Adolescent females should also be questioned about oral contraceptive use, given that about 5\% develop elevated blood pressure over a five-year period. ${ }^{136}$ Lastly, attention must be paid if the decision is made to treat hypertension with antihypertensive agents. The World Anti-Doping Agency, the US Olympic Committee, and the National Collegiate Athletic Association have banned several antihypertensive medications. ${ }^{136}$ Beta-blockers are banned in precision sports, such as archery, shooting, golf, and skiing. ${ }^{139}$ Also, all diuretics are banned because they can mask the presence of anabolic steroids. ${ }^{139}$

\section{Conclusion}

Hypertension in the pediatric population may soon comprise $20 \%$ of the estimated $60-75$ million of the US population with hypertension. The potential health consequences and financial cost to society related to this disorder could be staggering, and are just beginning to unfold. With proper education on hypertension and its harmful effects in children, pediatricians will assume a more pivotal role in the early detection of hypertension and be in an ideal position to institute preventive measures, particularly in the adolescent population.

\section{Disclosure}

The authors have no actual or perceived conflicts of interest to disclose in this work.

\section{References}

1. Sinaiko AR, Gomez-Marin O, Prineas RJ. Effect of low sodium diet or potassium supplementation on adolescent blood pressure. Hypertension. 1993;21:989-994.

2. Munter P, He J, Cutler JA, Wildman RP, Whelton PK. Trends in blood pressure among children and adolescents. JAMA. 2004;291: 2107-2113.

3. Sorof JM, Lai D, Turner J, Poffenbarger T, Portman RJ. Overweight, ethnicity, and the prevalence of hypertension in school-aged children. Pediatrics. 2004;113:475-482.

4. Falkner B, Gidding SS, Ramirez-Garnica G, Wiltrout SA, West D, Rappaport EB. The relationship of body mass index and blood pressure in primary care pediatric patients. J Pediatr. 2006;148:195-200.

5. Fields LE, Burt VL, Cutler JA, Hughes J, Roccella EJ, Sorlie P. The burden of adult hypertension in the United States 1999 to 2000: A rising tide. Hypertension. 2004;44:398-404.

6. Din-Dzietham R, Liu Y, Bielo MV, Shamsa F. High blood pressure trends in children and adolescents in national surveys, 1963-2002. Circulation. 2007;116:1488-1496.

7. Chobanian AV, Bakris GL, Black HR, et al. Seventh report of the joint national committee on prevention, detection, evaluation, and treatment of high blood pressure. Hypertension. 2003;42:1206-1252.

8. Flynn JT. Hypertension in adolescents. Adolesc Med Clin. 2005;16: $11-29$.

9. Luma GB, Spiotta RT. Hypertension in children and adolescents. Am Fam Physician. 2006;73:1158-1168.

10. Yamaguchi I, Flynn JT. Hypertension. In: Avner E, Harmon W, Niaudet P, Yoshikawa N, editors. Pediatric Nephrology. Berlin, Germany: Springer; 2009

11. National High Blood Pressure Education Program Working Group on High Blood Pressure in Children and Adolescents. The fourth report on the diagnosis, evaluation and treatment of high blood pressure in children and adolescents. Pediatrics. 2004;114:555-576.

12. Williams CL, Haymann LL, Daniels SR, et al; American Heart Association. Cardiovascular health in childhood. A statement for health professionals from the Committee on Atherosclerosis, Hypertension, and Obesity in the Young (AHOY) of the council on cardiovascular disease in the young. Circulation. 2002;106:143-160.

13. Urbina E, Alpert B, Flynn J, et al; American Heart Association Atherosclerosis, Hypertension, and Obesity in Youth Committee. Ambulatory blood pressure monitoring in children and adolescents: Recommendations for standard assessment: a scientific statement from the American Heart Association Atherosclerosis, Hypertension, and Obesity in Youth Committee of the Council on Cardiovascular Disease in the Young and the Council for High Blood Pressure Research. Hypertension. 2008;52:433-451. 
14. Wühl E, Witte K, Soergel M, Mehls O, Schaefer F; German Working Group on Pediatric Hypertension. Distribution of 24-h ambulatory blood pressure in children: Normalized reference values and role of body dimensions. J Hypertens. 2002;20:1995-2007.

15. Wilson DK, Sica DA, Miller SB. Ambulatory blood pressure nondipping status in salt-sensitive and salt-resistant black adolescents. Am J Hypertens. 1999;12:159-165.

16. Koshy S, MacArthur C, Luthra S, Gajaria M, Geary D. Ambulatory blood pressure monitoring: Mean blood pressure and blood pressure load. Pediatr Nephrol. 2005;20:1484-1486.

17. Wühl E, Hadtstein C, Mehls O, Schaefer F; Escape Trial Group. Home, clinic, and ambulatory blood pressure monitoring in children with chronic renal failure. Pediatr Res. 2004;55:492-497.

18. Sorof JM, Alexandrov AV, Cardwell G, Portman RJ. Carotid artery intimal-medial thickness and left ventricular hypertrophy in children with elevated blood pressure. Pediatrics. 2003;111:61-66.

19. Mitsnefes M, Flynn J, Cohn S, et al; CKID Study Group. Masked hypertension associates with left ventricular hypertrophy in children with CKD. J Am Soc Nephrol. 2010;21:137-144.

20. Lande MB, Carson NL, Roy J, Meagher CC. Effects of childhood primary hypertension on carotid intima media thickness: A matched controlled study. Hypertension. 2006;48:40-44.

21. Swartz SJ, Srivaths PR, Croix B, Feig DI. Cost-effectiveness of ambulatory blood pressure monitoring in the initial evaluation of hypertension in children. Pediatrics. 2008;122:1177-1181.

22. Agarwal R, Light RP. The effect of measuring ambulatory blood pressure on nighttime sleep and daytime activity - implications for dipping. Clin J Am Soc Nephrol. 2010;5:281-285.

23. Paradis G, Lambert M, O'Loughlin J, Lavallee C, et al. Blood pressure and adiposity in children and adolescents. Circulation. 2004;110: 1832-1838.

24. McNiece KL, Poffenbarger TS, Turner JL, Franco KD, Soroff JM, Portman RJ. Prevalence of hypertension and pre-hypertension among adolescents. J Pediatr. 2007;150:640-644.

25. Sorof JM, Cardwell G, Franco K, Portman RJ. Ambulatory blood pressure and left ventricular mass index in hypertensive children. Hypertension. 2002;39:903-908.

26. Richey PA, DiSessa TG, Hastings MC, Somes GW, Alpert BS, Jones DP. Ambulatory blood pressure and increased left ventricular mass in children at risk for hypertension. J Pediatr. 2008;152:343-348.

27. Hanevold C, Waller J, Daniels S, Portman R, Sorof J. The effects of obesity, gender, and ethnic group on left ventricular hypertrophy and geometry in hypertensive children: A collaborative study of the International Pediatric Hypertension Association. Pediatrics. 2004;113: 328-333.

28. Litwin M, Nieemirska A, Sladowska J, et al. Left ventricular hypertrophy and wall thickening in children with essential hypertension. Pediatr Nephrol. 2006;21:811-819.

29. Sorof JM, Poffenbarger T, Franco K, Portman R. Evaluation of whitecoat hypertension in children: Importance of the definitions of normal ambulatory blood pressure and the severity of casual hypertension. $\mathrm{Am}$ J Hypertens. 2001;14:855-860.

30. Stabouli S, Kotsis V, Toumanidis S, Papamichael C, Constantopoulous A, Zakopoulos N. White-coat and masked hypertension in children: Association with target organ damage. Pediatr Nephrol. 2005;20: 1151-1155.

31. Matsuoka S, Kawamura K, Honda M, Awazu M. White coat effect and white coat hypertension in pediatric patients. Pediatr Nephrol. 2002;17: 950-953.

32. Kavey RE, Kveselis DA, Atallah N, Smith FC. White coat hypertension in childhood: Evidence for end-organ effect. J Pediatr. 2007;150: 491-497.

33. Lurbe E, Torro I, Alvarez V, et al. Prevalence, persistence, and clinical significance of masked hypertension in youth. Hypertension. 2005;45: 493-498.

34. Matsuoka S, Awazu M. Masked hypertension in children and young adults. Pediatr Nephrol. 2004;19:651-654.

35. Maggio AB, Aggoun Y, Marchand LM, et al. Associations among obesity, blood pressure, and left ventricular mass. J Pediatr. 2008;152: 489-493.
36. Calzolari A, Giordano U, Matteucci MC, et al. Hypertension in young patients after renal transplantation: Ambulatory blood pressure monitoring verses casual blood pressure. Am J Hypertens. 1998;11: 497-501.

37. Giordano U, Matteucci MC, Calzolari A, Turchetta A, Rizzoni G, Alpert BS. Ambulatory blood pressure monitoring in children with aortic coarctation and kidney transplantation. J Pediatr. 2000;136: 520-523.

38. Palatini P, Julius $\mathrm{S}$. Heart rate and the cardiovascular risk. J Hypertens. 1997;15:1-37.

39. Julius S, Valentini M, Palatini P. Overweight and hypertension: A 2 way street? Hypertension. 2000;35:807-813.

40. Liu JE, Roman MJ, Pini R, Schwartz JE, Pickering TG, Devereux RB. Cardiac and arterial target organ damage in adults with elevated ambulatory and normal office blood pressure. Ann Intern Med. 1999; 131:564-572.

41. Lubrano R, Travasso E, Raggi C, Guido G, Masciangelo R, Elli M. Blood pressure load, proteinuria and renal function in pre-hypertensive children. Pediatr Nephrol. 2009;24:823-831.

42. Cuspidi C, Lonati L, Sampieri L, et al. Prevalence of target organ damage in treated hypertensive patients: Different impact of clinic and ambulatory blood pressure control. J Hypertens. 2009;18:803-809.

43. Dursun H, Bayazit AK, Cengiz N, et al. Ambulatory blood pressure monitoring and renal functions in children with a solitary kidney. Pediatr Nephrol. 2007;22:559-564.

44. Patzer L, Seeman T, Luck C, Wuhl E, Janda J, Misselwitz L. Day and night time blood pressure elevation in children with higher grades of renal scarring. $J$ Pediatr. 2003;142:117-122.

45. Klahr S, Levey AS, Beck GJ. The effects of dietary protein restriction and blood-pressure control on the progression of chronic renal disease. N Engl J Med. 1994;330:877-884.

46. Sarnak MJ, Greene T, Wang X, et al. The effects of a lower target blood pressure on the progression of kidney disease: Long-term follow-up of the Modification of Diet in Renal Disease study. Ann Intern Med. 2005; 142:342-351.

47. Wühl E, Trivelli A, Picca S, et al; ESCAPE trial group. Strict bloodpressure control and progression of renal failure in children. $N$ Engl $J$ Med. 2009;361:1639-1650.

48. Feld LG, Springate JE. Hypertension in children. Curr Probl Pediatr. 1988;18:317-373

49. Brewer E. Evaluation of hypertension in childhood diseases. In: Avner E, Harmon W, Niaudet P, Yoshikawa N, editors. Pediatric Nephrology. Berlin, Germany: Springer; 2009.

50. Robinson RF, Batisky DL, Hayes JR, Nahata MC, Mahan JD. Body mass index in primary and secondary pediatric hypertension. Pediatr Nephrol. 2004;19:1379-1384.

51. Flynn JT, Alderman MH. Characteristics of children with primary hypertension seen at a referral center. Pediatr Nephrol. 2005;20: 961-966.

52. Barlassina C, Lanzani C, Manunta P, Bianchi G. Genetics of essential hypertension: From families to genes. J Am Soc Nephrol. 2002;13: S155-S164.

53. Appel LJ, Giles TD, Black HR, et al. ASH Position paper: Dietary approaches to lower blood pressure. J Am Soc Hypertens. 2010;4: 79-89.

54. Couch SC, Saelens BE, Levin L, Dart K, Falciglia G, Daniels SR. The efficacy of a clinic-based behavioral nutrition intervention emphasizing a DASH-type diet for adolescents with elevated blood pressure. J Pediatr. 2008;152:494-501.

55. Geleijnse JM, Kok FJ, Grobbee DE. Blood pressure response to changes in sodium and potassium intake: A metaregression analysis of randomized trials. J Hum Hypertens. 2003;17:471-480.

56. Adrogue HJ, Madias NE. Sodium and potassium in the pathogenesis of hypertension. N Engl J Med. 2007;356:1966-1978.

57. Cutler JA, Follmann D, Allender PS. Randomized trials of sodium reduction: An overview. Am J Clin Nutr. 1997;65:S643-S651.

58. Graudal NA, Galloe AM, Garred P. Effects of sodium restriction on blood pressure, renin, aldosterone, catecholamines, cholesterol and triglycerides: A meta-analysis. JAMA. 1998;279: $1383-1391$. 
59. Intersalt Cooperative Research Group. INTERSALT: An international study of electrolyte excretion and blood pressure: Results for 24-hour urinary sodium and potassium excretion. BMJ. 1988;297:319-328.

60. Sacks FM, Svetkey LP, Vollmer WM, et al. DASH-Sodium Collaborative Research Group. Effects on blood pressure of reduced dietary sodium and the Dietary Approaches to Stop Hypertension (DASH) diet. $N$ Engl J Med. 2001;344:3-10.

61. Rodriguez-Iturbe B, Romero F, Johnson RJ. Pathophysiological mechanisms of salt-dependent hypertension. Am J Kidney Dis. 2007;4: 655-672.

62. Whelton PK, He J, Cutler JA, et al. Effects of oral potassium on blood pressure: Meta-analysis of randomized controlled clinical trials. JAMA. 1997;277:1624-1632.

63. Bender AM, Donnerstein RL, Samson RA, Zhu D, Goldberg SJ. Hemodynamic effects of acute caffeine ingestion in young adults. Am J Cardiol. 1997;79:696-699.

64. Waring WS, Goudsmit J, Marwick J, Webb DJ, Maxwell SRJ. Acute caffeine intake influences central more than peripheral blood pressure in young adults. Am J Hypertens. 2003;16:919-924.

65. Casiglia E, Bongiovi S, Paleari CD, et al. Haemodynamic effects of coffee and caffeine in normal volunteers: A placebo-controlled clinical study. J Intern Med. 1991;229:501-504.

66. Pincomb GA, Lovallo WR, Passey RB, Whitsett TL, Silverstein SM, Wilson MF. Effects of caffeine on vascular resistance, cardiac output and myocardial contractility in young men. Am J Cardiol. 1985;56: 119-122.

67. Evoniuk G, von Borstel RW, Wurtman RJ. Antagonism of the cardiovascular effects of adenosine by caffeine or 8-(p-sulfophenyl) theophylline. J Pharmacol Exp Ther. 1987;240:428-432.

68. Chen L, Caballero B, Mitchell DC, et al. Reducing consumption of sugar-sweetened beverages is associated with reduced blood pressure: A prospective study among United States adults. Circulation. 2010;121: 2398-2406.

69. Nguyen S, Choi HK, Lustig RH, Hsu CY. Sugar-sweetened beverages, serum uric acid, and blood pressure in adolescents. J Pediatr. 2009;154: 807-813.

70. Jalal DI, Smits G, Johnson RJ, Chonchol M. Increased fructose associates with elevated blood pressure. J Am Soc Nephrol. 2010;32: 1543-1549.

71. Neilson EG. The fructose nation. J Am Soc Nephrol. 2007;18: 2619-2621.

72. Johnson RJ, Segal MS, Sautin Y, et al. Potential role of sugar (fructose) in the epidemic of hypertension, obesity and the metabolic syndrome, diabetes, kidney disease, and cardiovascular disease. Am J Clin Nutr. 2007;86:899-906.

73. Feig DI, Kang DH, Johnson RJ. Uric acid and cardiovascular risk. N Engl J Med. 2008;359:1811-1821.

74. Kotsis V, Stabouli S, Papakatsika S, Rizos Z, Parati G. Mechanisms of obesity-induced hypertension. Hypertens Res. 2010;33:386-393.

75. Goldstein DS. Plasma catecholamines and essential hypertension An analytical review. Hypertension. 1983;1:86-99.

76. Grassi G, Seravalle G, Cattaneo BM, et al. Sympathetic activation in obese normotensive subjects. Hypertension. 1995;25:560-563.

77. Wofford MR, Anderson DC Jr, Brown CA, Jones DW, Miller ME, Hall JE. Antihypertensive effect of alpha- and beta-adrenergic blockade in obese and lean hypertensive subjects. Am J Hypertens. 2001; 7: 694-698.

78. Hall JE. Mechanisms of abnormal renal sodium handling in obesity hypertension. Am J Hypertens. 1997;10:49S-55S

79. Ruano M, Silvestre V, Castro R. Morbid obesity, hypertensive disease and the renin-angiotensin-aldosterone axis. Obes Surg. 2005;15: $670-676$

80. Hall JE, Brands MW, Dixon WN, Smith MJ. Obesity-induced hypertension. Renal function and systemic hemodynamics. Hypertension. 1993;22:292-299.

81. Rocchini AP. Obesity hypertension. Am J Hypertens. 2002;15: 50S-52S.
82. Kotchen TA. Obesity-related hypertension: Epidemiology, pathyphysiology, and clinical management. Am J Hypertens. 2010;23: 1170-1178.

83. Rasouli N, Kern PA. Adipocytokines and the metabolic complications of obesity. J Clin Endocrinol Metab. 2008;93:S64-S73.

84. Hall JE, Hildebrandt DA, Kuo J. Obesity hypertension: Role of leptin and sympathetic nervous system. Am J Hypertens. 2001;14: $103 \mathrm{~S}-115 \mathrm{~S}$.

85. Meyers MR, Gokce N. Endothelial dysfunction in obesity: Etiological role in atherosclerosis. Curr Opin Endocrinol Diabetes Obes. 2007;14: 365-369.

86. Sacks FM, Campos H. Dietary therapy in hypertension. $N$ Engl J Med. 2010;362:2102-2112.

87. Appel LJ, Moore TN, Obarzanek E, et al. A clinical trial of the effects of dietary patterns on blood pressure. DASH Collaborative Research Group. N Engl J Med. 1997;336:1117-1124.

88. Hagberg JM, Park JJ, Brown MD. The role of exercise training in the treatment of hypertension: An update. Sports Med. 2000;30: 193-206

89. Torrance, B, McGuire KA, Lewanczuk R, McGavock J. Overweight, physical activity and high blood pressure in children: A review of the literature. Vasc Health Risk Manag. 2007;3:139-149.

90. Farpour-Lambert NJ, Aggoun Y, Marchand LM, Martin XE, Herrmann FR, Beghetti M. Physical activity reduces systemic blood pressure and improves early markers of atherosclerosis in pre-pubertal obese children. J Am Coll Cardiol. 2009;54: 2396-2406

91. Litwin M, Niemirska A, Sladowska-Kozlowska J, et al. Regression of target organ damage in children and adolescents with primary hypertension. Pediatr Nephrol. 2010;25:2489-2499.

92. Ellis D. Management of the hypertensive child. In: Avner E, Harmon W, Niaudet P, Yoshikawa N, editors. Pediatric Nephrology. Berlin, Germany: Springer; 2009.

93. Silverstein DM, Champoux E, Aviles DH, Vehaskari VM. Treatment of primary and secondary hypertension in children. Pediatr Nephrol. 2006;21:820-827.

94. Sorof JM, Cargo P, Graepel J, et al. Beta-blocker/thiazide combination for treatment of hypertensive children: A randomized double-blind, placebo-controlled trial. Pediatr Nephrol. 2002;17: 345-350.

95. Soffer B, Zhang Z, Miller K, Vogt BA, Shahinfar S. A double-blinded, placebo-controlled, dose-response study of the effectiveness and safety of lisinopril for children with hypertension. Am J Hypertens. 2003;16: 975-800.

96. Graves JW, Althaf MM. Utility of ambulatory blood pressure monitoring in children and adolescents. Pediatr Nephrol. 2006;21: 1640-1652.

97. Belsha CW, Wells TG, McNiece KL, Seib PM, Plummer JK, Berry PL. Influence of diurnal blood pressure variations on target organ abnormalities in adolescents with mild essential hypertension. Am J Hypertens. 1998;11:410-417.

98. Brem AS. Insights into glucocorticoid-associated hypertension. Am J Kidney Dis. 2001;37:1-10.

99. Mantero F, Boscaro M. Glucocorticoid-dependent hypertension. J Steroid Biochem Mol Biol. 1992;43:409-413.

100. Sato A, Suzuki H, Murakami M, Nakazato Y, Iwaita Y, Saruta T. Glucocortocoid increases angiotensin II type I receptor and its gene expression. Hypertension. 1994;23:25-30.

101. Scherrer U, Vissing SF, Morgan BJ, et al. Cyclosporine-induced sympathetic activation and hypertension after heart transplantation. N Engl J Med. 1990;323:693-699.

102. Dhaun N, Goddard J, Webb DJ. The endothelin system and its antagonism in chronic kidney disease. J Am Soc Nephrol. 2006;17: 943-955.

103. McAreavey D, Cumming AMM, Boddy K. The renin-angiotensin system and total body sodium and potassium in hypertensive women taking oestrogen-progestagen oral contraceptives. Clin Endocrinol (Oxf). 1983;18:111-118. 
104. Weir MR. Renal effects of nonselective NSAIDs and coxibs. Cleve Clin J Med. 2002;69:S153-S158.

105. Nzerue CM, Hewan-Lowe K, Riley LJ Jr. Cocaine and the kidney: A synthesis of pathophysiologic and clinical perspectives. Am J Kidney Dis. 2000;35:783-795.

106. Berman JA, Setty A, Steiner MJ, Kaufman KR, Skotzko C. Complicated hypertension related to the abuse of ephedrine and caffeine alkaloids. $J$ Addict Dis. 2006;25:45-48.

107. Vaziri ND. Cardiovascular effects of erythropoietin and anemia correction. Curr Opin Nephrol Hypertens. 2001;10:633-637.

108. Mitsnefes M, Stablein D. Hypertension in pediatric patients on long-term dialysis: A report of the North American Pediatric Renal Transplant Cooperative Study (NAPRTCS). Am J Kidney Dis. 2005; 45:309-315.

109. Mansoor GA. Herbs and alternative therapies in the hypertension clinic. Am J Hypertens. 2001;14:971-975.

110. Di Gennaro C, Barilli A, Giuffredi C, Gatti C, Montanari A, Vescovi PP. Sodium sensitivity of blood pressure in long-term detoxified alcoholics. Hypertension. 2000;35:869-874.

111. Narkiewicz K, van de Borne PJ, Hausberg M, et al. Cigarette smoking increases sympathetic outflow in humans. Circulation. 1998;98: 528-534.

112. Celermajer DS, Adams MR, Clarkson P, et al. Passive smoking and impaired endothelium-dependent arterial dilation in healthy young adults. $N$ Engl J Med. 1996;334:150-154.

113. US Teenage Pregnancies, Births and Abortions: National and State Trends and Trends by Race and Ethnicity. Guttmacher Institute January 2010 Report. Available at: www.guttmacher.org. Accessed April 10, 2011.

114. Roberts JM, Pearson G, Cutler J, Lindheimer M. Summary of the NHLBI working group on research on hypertension during pregnancy. Hypertension. 2003;41:437-445.

115. Sibai B, Dekker G, Kupferminc M. Pre-eclampsia. Lancet. 2005;365: 785-799.

116. Taylor RN, Varma M, Teng NN, Roberts JM. Women with preeclampsia have higher plasma endothelin levels than women with normal pregnancies. J Clin Endocrinol Metab. 1990;71:1675-1677.

117. Wang Y, Walsh SW, Kay HH. Placental lipid peroxides and thromboxane are increased and prostacyclin is decreased in women with preeclampsia. Am J Obstet Gynecol. 1992;167:946-949.

118. Conrad KP, Benyo DF. Placental cytokines and the pathogenesis of preeclampsia. Am J Reprod Immunol. 1997;37:240-249.

119. Baumwell S, Karumanchi SA. Pre-eclampsia: Clinical manifestations and molecular mechanisms. Nephron Clin Pract. 2007;106: c72-c81.

120. Gilbert JS, Ryan MJ, Lamarca BB, Dedeek M, Murphy SR, Granger JP. Pathophysiology of hypertension during preeclampsia: Linking placental ischemia with endothelial dysfunction. Am JPhysiol Heart Circ Physiol. 2008;294:H541-H550.

121. LaMarca BD, Gilbert J, Granger JP. Recent progress toward the understanding of the pathophysiology of hypertension during preeclampsia. Hypertension. 2008;51:982-988.

122. Yallampalli $C$, Garfield RE. Inhibition of nitric oxide synthesis in rats during pregnancy produces signs similar to those of preeclampsia. $\mathrm{Am}$ J Obstet Gynecol. 1993;69:1316-1320.
123. Molnar M, Suto T, Toth T, Hertelendy F. Prolonged blockade of nitric oxide synthesis in gravid rats produces sustained hypertension, proteinuria, thrombocytopenia, and intrauterine growth retardation. $\mathrm{Am}$ J Obstet Gynecol. 1994;170:1458-1466.

124. Geller DS, Farhi A, Pinkerton N, et al. Activating mineralocorticoid receptor mutation in hypertension exacerbated by pregnancy. Science. 2000;289:119-123.

125. Wagner SJ, Barac S, Garovic VD. Hypertensive pregnancy disorders: Current concepts. J Clin Hypertens. 2007;14:332-341.

126. Cooper WO, Hernandez-Diaz S, Arbogast PG, et al. Major congenital malformations after first-trimester exposure to ACE inhibitors. $N$ Engl J Med. 2006;354:2443-2451.

127. Christakis DA, Ebel BE, Rivara FP, Zimmerman FJ. Television, video, and computer game usage in children under 11 years of age. J Pediatr. 2004; 145:652-656.

128. Rideout V, Foehr U, Roberts D. Generation M: Media in the lives of 8-18 year-olds. The Henry J Kaiser Family Foundation. Available from: http://www.kff.org/entmedia/upload/Executive-SummaryGeneration-M-Media-in-the-Lives-of-8-18-Year-olds.pdf. Accessed April 10, 2011.

129. Del Rosario JD, Treiber F, Harshfield GA, Davies HC, Strong WB. Predictors of future ambulatory blood pressure in youth. $J$ Pediatr. 1998;132:693-698.

130. Borusiak P, Bouikidis A, Liersch R, Russell JB. Cardiovascular effects in adolescents while they are playing video games: A potential health risk factor? Psychophysiology. 2008;45:327-332.

131. Roemmich JN, Feda DM, Seelbinder AM, Lambiase MJ, Kala GK, Dorn J. Stress-induced cardiovascular reactivity and atherogenesis in adolescents. Atherosclerosis. 2011;215:465-470.

132. Kaplan NM. Gidding SS, Pickering TG, Wright JT Jr. 36th Bethesda Conference. Systemic hypertension. J Am Coll Cardiol. 2005; 45:1346-1348.

133. Tanji JL. Tracking of elevated blood pressure values in adolescent athletes at 1-year follow-up. Am J Dis Child. 1991;145:665-667.

134. Pelliccia A. Athlete's heart and hypertrophic cardiomyopathy. Curr Cardiol Rep. 2000;2:166-171.

135. Mahmud A, Feely J. Spurious systolic hypertension of youth: Fit men with elastic arteries. Am J Hypertens. 2003;16:229-232.

136. Leddy JJ, Izzo J. Hypertension in athletes. J Clin Hypertens. 2009;11: 226-233.

137. McCambridge TM, Benjamin HJ, Brenner JS, et al. Athletic participation by children and adolescents who have systemic hypertension. Pediatrics. 2010;125:1287-1294.

138. Mitchell JH, Haskell W, Snell P, Van Camp SP. 36th Bethesda conference. Classification of sports. J Am Coll Cardiol. 2005;45:1364-1367.

139. WADA. The World Anti-Doping Code. The 2011 Prohibited List. International Standard. Montreal, Canada: WADA;2011. Available from: http://www.wada-ama.org/en/World-Anti-Doping-Program/ Sports-and-Anti-Doping-Organizations/International-Standards/ Prohibited-List/. Accessed April 10, 2011.
Adolescent Health, Medicine and Therapeutics

\section{Publish your work in this journal}

Adolescent Health, Medicine and Therapeutics is an international, peer-reviewed, open access journal focusing on health, pathology, and treatment issues specific to the adolescent age group. All aspects of health maintenance, preventative measures and disease treatment interventions are addressed within the journal and practitioners from

\section{Dovepress}

all disciplines are invited to submit their work as well as healthcare researchers and patient support groups.. The manuscript management system is completely online and includes a very quick and fair peerreview system. Visit http://www.dovepress.com/testimonials.php to read real quotes from published authors. 